\title{
Mesospheric gravity wave characteristics and identification of their sources around spring equinox over Indian low latitudes
}

\author{
M. Sivakandan ${ }^{1}$, I. Paulino ${ }^{2}$, A. Taori ${ }^{1, a}$, and K. Niranjan ${ }^{3}$ \\ ${ }^{1}$ National Atmospheric Research Laboratory (NARL), Gadanki, 517112, India \\ ${ }^{2}$ Universidade Federal de Campina Grande (UFCG), Campina Grande, Brazil \\ ${ }^{3}$ Department of Physics, Andhra University, Visakhapatnam, 530003, India \\ ${ }^{a}$ now at: National Remote Sensing Center (NRSC), Hyderabad, 500037, India \\ Correspondence to: A. Taori (alok.taori@gmail.com)
}

Received: 17 July 2015 - Published in Atmos. Meas. Tech. Discuss.: 7 August 2015

Revised: 27 November 2015 - Accepted: 9 December 2015 - Published: 18 January 2016

\begin{abstract}
We report OI557.7 nm night airglow observations with the help of a charged-couple device (CCD)-based allsky camera from a low-latitude station, Gadanki $\left(13.5^{\circ} \mathrm{N}\right.$; $79.2^{\circ} \mathrm{E}$ ). Based on the data collected during March and April over 3 years, from 2012 to 2014 (except March 2013), we characterize the small-scale gravity wave properties. During this period, 50 gravity wave events were detected. The horizontal wavelengths of the gravity waves are found to ranging from 12 to $42 \mathrm{~km}$ with the phase velocity $20-90 \mathrm{~m} \mathrm{~s}^{-1}$. In most cases, these waves were propagating northward with only a few occurrences of southward propagation. In the present novel investigation from the Indian sector, each of the wave events was reverse-ray-traced to its source. The outgoing longwave radiation (OLR) suggested that tropospheric convection was a possible source for generation of the observed waves. It was found that approximately $66 \%$ of the events were triggered directly by the convection.
\end{abstract}

\section{Introduction}

The variability in the middle-atmospheric parameters (e.g., temperature, wind and airglow intensities) is often attributed to the energy and momentum deposition by gravity waves (e.g., Fritts and Alexander, 2003). There are many techniques to study the gravity waves in the middle and upper atmosphere, such as radio, optical, and in situ, as well as spaceborne. In order to observe the gravity wave parameters in the atmosphere, radars, lidars, photometers, rockets, and satellite instruments have been used (e.g., Smith, 2012). However, understanding the role of small-scale gravity waves in the mesosphere-lower-thermosphere dynamics remains a challenging task. In this regard, ground-based airglow imaging is an important tool to estimate the gravity wave signatures. The primary advantage of the imaging is that it provides a twodimensional view at the chosen airglow emission, and thus it has the capability to determine the horizontal scales and propagation direction of the gravity waves. Further, at a given place it provides the temporal evolution of the gravity-waveinduced oscillations. As the field of view of imagers at mesospheric altitudes may cover a horizontal distance of 300$350 \mathrm{~km}$, such measurements are highly suited for waves having small scales (horizontal wavelength $<150 \mathrm{~km}$ ), short periods (periods $<1 \mathrm{~h}$ ), and long vertical wavelengths $(>10 \mathrm{~km}$ ) (Liu and Swenson, 2003).

For about 3 decades, capabilities of airglow imaging have been widely utilized to analyze the gravity wave characteristics (e.g., Taylor and Hapgood, 1988; Nakamura et al., 1999; Walterscheid et al., 1999; Medeiros et al., 2003; Ejiri et al., 2003; Kim et al., 2010; Q. Li et al., 2011; Z. Li et al., 2011). Particularly, Nakamura et al. (1999) utilized 18 months of $\mathrm{OH}$ imager observations at Shigaraki $\left(34.9^{\circ} \mathrm{N}\right.$, $\left.136.1^{\circ} \mathrm{E}\right)$ and reported that the gravity waves propagated eastward (westward) in summer (winter), with horizontal wavelength varying from 10 to $45 \mathrm{~km}$. Medeiros et al. (2003) analyzed 12 months of observations at Cachoeira Paulista $\left(23^{\circ} \mathrm{S}, 45^{\circ} \mathrm{W}\right)$ and found that gravity waves exhibited preferential propagation directions, with southeast propagation in summer and northwest in winter. Using 1 year of $\mathrm{OH}$ Meinel and OI $(557.7 \mathrm{~nm})$ band image data from Rikubetsu 
$\left(43.5^{\circ} \mathrm{N}, 143.8^{\circ} \mathrm{E}\right)$ and Shigaraki $\left(34.9^{\circ} \mathrm{N}, 136.1^{\circ} \mathrm{E}\right)$, Ejiri et al. (2003) reported that gravity waves propagated mostly to the north or northeast during the summer. However, gravity waves propagated to the west at Rikubetsu and to the southwest at Shigaraki during the winter. In a more recent report, Kim et al. (2010) used $\mathrm{OH}, \mathrm{O}_{2}$, and $\mathrm{OI} 557.7 \mathrm{~nm}$ data from Mt. Bohyun $\left(36.2^{\circ} \mathrm{N}, 128.9^{\circ} \mathrm{E}\right)$ and found that gravity waves propagate westward during fall and winter and eastward during spring and summer.

From the Indian sector, there are also several reports (e.g., Mukherjee 2003, 2010; Pragati et al., 2010; Lakshmi Narayanan and Gurubaran, 2013; Parihar and Taori, 2015) which document the small-scale gravity wave characteristics. For example, using 5 months of $\mathrm{OH}$ airglow imager data from January to May 2008 at Allahabad $\left(25.45^{\circ} \mathrm{N}, 81.85^{\circ} \mathrm{E}\right)$, Pragati et al. (2010) reported that most of the small-scale gravity waves propagate to the north and northeast in March and May. Furthermore, using the same data set, Mukherjee et al. (2010) studied the wind filtering effect on the gravity waves. Likewise, during 2007 Lakshmi Narayanan and Gurubaran (2013) reported the seasonal variation of the gravity wave characteristics over Tirunelveli $\left(8.71^{\circ} \mathrm{N}, 77.81^{\circ} \mathrm{E}\right)$. Recently, Parihar and Taori (2015) investigated the longdistance propagating gravity waves using the coordinated bi-station airglow data (Airglow photometer over Gadanki $\left(13.5^{\circ} \mathrm{N}, 79.2^{\circ} \mathrm{E}\right)$ and all-sky airglow imager over Allahabad $\left(25.5^{\circ} \mathrm{N}, 81.9^{\circ} \mathrm{E}\right)$ ). They concluded that convection might be a source of the noted long-distance gravity wave events. However, none of these reports addressed the exact sources of the waves.

It is important to note that, in a tropical location, dependence on optically clear sky makes the statistics biased. Therefore, in the present report we have taken the data in March-April 2012 and 2014 and April 2013, when the maximum number of cloud-free nights are monitored (e.g., Taori et al., 2012) over Gadanki (13.5 $\left.\mathrm{N} ; 79.2^{\circ} \mathrm{E}\right)$. To our knowledge for the first time in the Indian sector, we show the gravity wave characteristics together with the reverse-ray-traced sources of these waves. We use outgoing longwave radiation (OLR) obtained from the National Oceanic and Atmospheric Administration (NOAA) for the above purpose.

\section{Instrumentation and data analysis}

The all-sky airglow imager of the National Atmosphere Research Laboratory (NARL) was installed in March 2012 at Gadanki $\left(13.5^{\circ} \mathrm{N}, 79.2^{\circ} \mathrm{E}\right)$. Since then, this NARL airglow imager (NAI) has carried out regular night airglow observations during moonless, cloudless nights. The front optics of NAI uses a fish eye lens having a field of view (FOV) of $180^{\circ}$ (current FOV is limited to $117^{\circ}$ due to NAI housing to avoid the background illumination at low elevation and to avoid nonlinearity of the pixels at higher zenith angles). Its filter chamber contains three different interference filters, namely $840 \mathrm{~nm}$ for $\mathrm{OH}$ emission (peak altitude $\sim 87 \mathrm{~km}$ ), OI557.7 $\mathrm{nm}$ emission (peak altitude $\sim 97 \mathrm{~km}$ ), and OI630 $\mathrm{nm}$ emission (peak altitude $\sim 250 \mathrm{~km}$ ). In order to maintain the constant temperature, a thermoelectric temperature controller is attached to the filter chamber. A camera lens focuses the light on the PIXIS-1024B charge-coupled device (CCD) sensor, which is thermoelectrically cooled. In the present setup, we bin the images to $2 \times 2$ pixels, making an effective $512 \times 512$ super-pixel image on the chip to enhance the signal-to-noise ratio. Depending on the compromise between the background luminosity, interference filter transmission, and actual airglow brightness, currently exposure times are $15 \mathrm{~s}$ for $\mathrm{OH}$ and $110 \mathrm{~s}$ for both OI557.7 nm and OI630 nm emission monitoring. The imager was optimized to view OI557.7 $\mathrm{nm}$ as well as OI630 $\mathrm{nm}$ emissions together with $\mathrm{OH}(840 \mathrm{~nm})$. Further details about the NAI are given in Taori et al. (2013).

In this present study, we could get 32 clear-sky night data. From raw images we have cropped the images for $117^{\circ}$ full field of view to remove the background walls of our laboratory from the images. Furthermore, we unwarped the images for barrel distortions to linearize the scales. This, however, does not introduce any significant difference in the wavelength estimation as the error is a function of pixel size on which the image is focused, which in the present case is $\sim 0.8 \mathrm{~km}$. At last we enhance the wave fronts by contrast adjustment (for better visibility). In order to remove the stars, we used a median filter. In the processed images so obtained, continuous bright and dark bands which persist in more than three consecutive images are considered as the structure depicting a wave event. This analysis is performed on all the data. We note that, in 32 days of data, 50 wave events were prominent and exhibited a clear horizontal propagation. An example of a gravity wave event is shown in Fig. 1. It emphasizes the presence of consecutive bright and dark bands (green-colored box). The yellow line with an arrow denotes the wave propagation direction. The propagation is identified by cross-correlating the position of these fronts from one image to another in consecutive images. Furthermore, the estimate of propagation angle is done by measuring the angle between the yellow line (with an arrow indicating the direction of propagation) with the horizontal line parallel to the north direction. For angle measurement $0^{\circ}$ belongs to the noth direction and the angle of increment is taken from clockwise direction. In order to get the horizontal wavelength of the observed wave event, we took the perpendicular pixels of wave phase (yellow-colored arrows) and plotted the gray count values. The distance between two peaks provides the horizontal wavelength estimates (in this particular wave event, horizontal wavelength is estimated to be $\sim 14 \mathrm{~km})$. To calculate a phase velocity $\left(V_{\mathrm{p}}=\right.$ displacement/time-difference) of the wave event, first we calculate the phase displacement of the wave from one image to another (for example, if the position of a wave phase is $\left(x_{1}, y_{1}\right)$ in the first image and in the second image the position is $\left(x_{2}, y_{2}\right)$, then the displacement is de- 

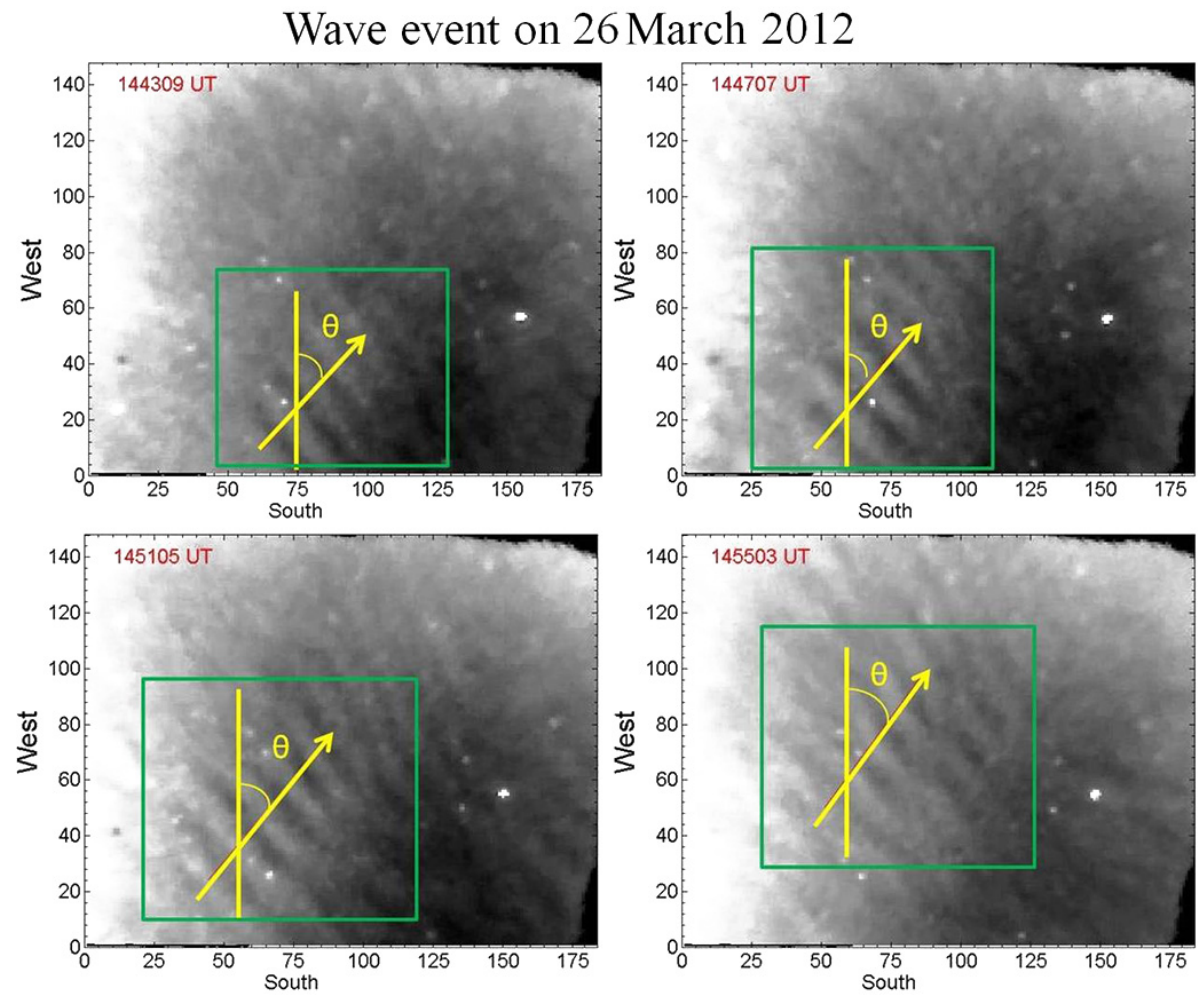

Figure 1. A sample figure of observed gravity wave event in OI557.7 nm emisison on 26 March 2012. The yellow arrows reveal their propagation direction at an angle $\Theta$ (angle of increment is from $0^{\circ}$ north clockwise). The green-colored box shows the dominant wave fronts.

fined as $\left.d=\sqrt{\left(x_{2}-x_{1}\right)^{2}+\left(y_{2}-y_{1}\right)^{2}}\right)$. In the case shown, the observed phase velocity is $\sim 23 \mathrm{~m} \mathrm{~s}^{-1}$, and the angle of wave propagation is $\sim 55^{\circ}$.

We performed this analysis on the full data set (i.e., 50 wave events of which 21 events in the year 2012, 5 events in the year 2013, and 24 events in the year 2014), and wave characteristics obtained as explained above are presented in this report.

\section{Ray-tracing method}

According to Lighthill (1978), if a gravity wave packet is propagating in a fluid with the background wind $\boldsymbol{V}(\boldsymbol{x})=$ $(u v w)$, then its evolution can be described by

$\frac{\mathrm{d} x_{i}}{\mathrm{~d} t}=V_{i}+\frac{\partial \omega_{\mathrm{Ir}}}{\partial k_{i}}=V_{i}+c_{\mathrm{gi}}$

and

$\frac{d k_{i}}{\mathrm{~d} t}=-k_{j} \frac{\partial V_{j}}{\partial x_{i}}-\frac{\partial \omega_{\mathrm{Ir}}}{\partial x_{i}}$,

where $\omega_{\mathrm{Ir}}=\omega_{\mathrm{Or}}-\boldsymbol{k} \boldsymbol{V}$ is the intrinsic frequency of the gravity waves, $\omega_{\mathrm{Or}}$ is the observed frequency, $\boldsymbol{k}$ is the wave vector, $\boldsymbol{x}$ is the position of the wave at a given time, $c_{\mathrm{gi}}$ is the group velocity, $i j=1,2,3$, and repeated indices imply a summation. It means that the temporal evolution of a gravity wave in the atmosphere can be followed if its position and wave vector are known, at a given time. However, the knowledge of background wind and temperature are necessary as well.

The reverse ray tracing starts at the observatory coordinates and airglow layer peak height, i.e., $\boldsymbol{x}(t=0)=$ $(x, y, z)=\left(79.2^{\circ} \mathrm{E}, 13.5^{\circ} \mathrm{N}, 97 \mathrm{~km}\right)$. The initial wave vector was taken from the OI557.7 nm images and from the dispersion relation, that is, $\boldsymbol{k}(t=0)=(k, l, m)=\left(\frac{2 \pi}{\lambda_{x}}, \frac{2 \pi}{\lambda_{y}}, m\right)$, where $\lambda_{H}^{2}=\lambda_{x}^{2}+\lambda_{y}^{2}$ is the horizontal wavelength. The vertical wave number at the OI557.7 nm layer was obtained using the Marks and Eckermann (1995) dispersion relation, which excludes acoustic waves, i.e.,

$m^{2}=\frac{\left(k^{2}+l^{2}\right) N^{2}}{\omega_{\text {Ir }}^{2}}-\left(k^{2}+l^{2}\right)-\frac{1}{4 H^{2}}$,

where $N^{2}$ is the buoyancy frequency and $H$ is the scale height.

The background wind used as the input to the ray-tracing model was based on the Horizontal Wind Model (HWM-07; Drob et al., 2008), and the temperature profiles were obtained from Naval Research Laboratory Mass Spectrometer and Incoherent Scatter Radar model (NRLMSISE-00; Picone et al., 2002). In addition, comparison between the ray paths for the gravity waves using HWM and no wind conditions were made in order to evaluate the effects of the wind in the prop- 


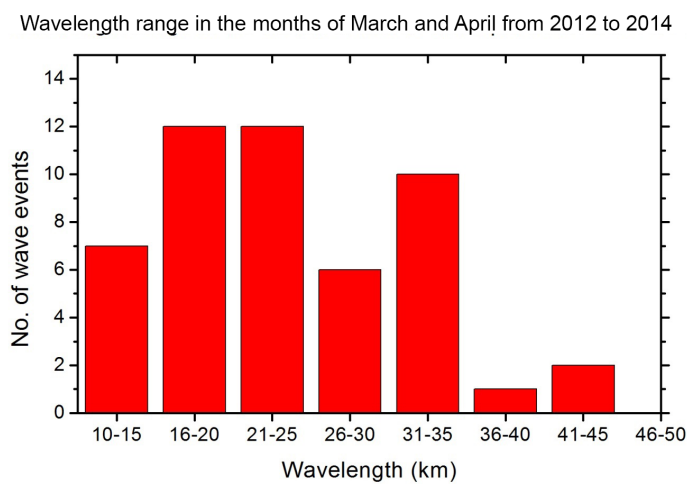

Figure 2. The distribution of horizontal wavelengths of all the waves observed.

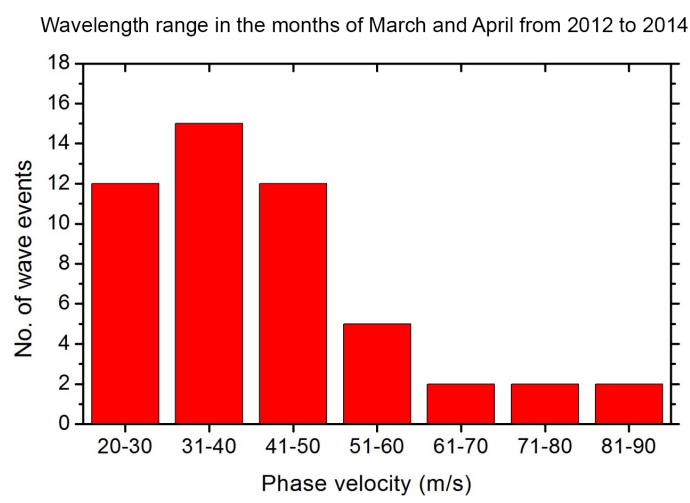

Figure 3. The distribution of the phase velocity of all the waves observed.

agation of the gravity waves. Further description about this ray-tracing model can be found in Vadas and Fritts (2005, 2009) and Paulino et al. (2012).

\section{Results and discussion}

\subsection{Range of parameters found}

First, we present the composite results for the years 20122014 to show the overview of the results. horizontal wavelengths of the wave events are from 10 to $42 \mathrm{~km}$ (Fig. 2). Among this distribution, about half of the wave events have their horizontal wavelengths in the $10-25 \mathrm{~km}$ range, and $22 \%$ of the wave events were noted in the $30-35 \mathrm{~km}$ wavelength range. It is evident from Fig. 2 that more than $90 \%$ of wave events have wavelength less than $35 \mathrm{~km}$. The estimated horizontal phase velocity distribution of the wave events is shown in Fig. 3. Phase velocity of the noted wave events are $20-90 \mathrm{~m} \mathrm{~s}^{-1}$. From this $\sim 78 \%$ of the wave events show the phase velocity less than $50 \mathrm{~m} \mathrm{~s}^{-1}$. Using the observed horizontal wavelength and phase speed, we have calculated the observed period of the wave events, which is shown in Fig. 4. The observed period of the gravity waves is $4-20 \mathrm{~min}$. And

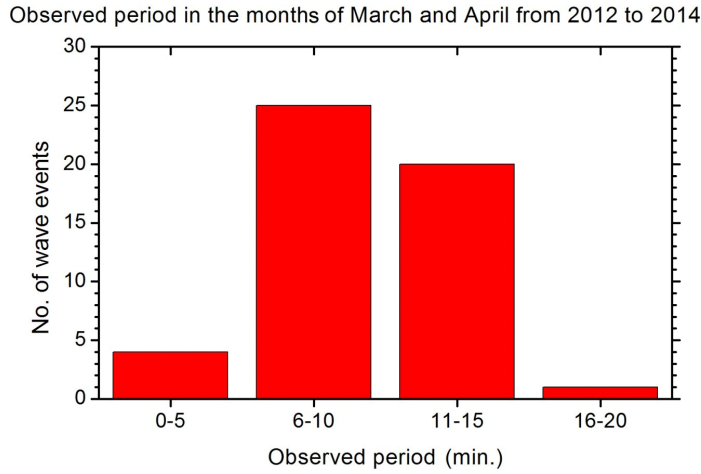

Figure 4. The distribution of observed periods.
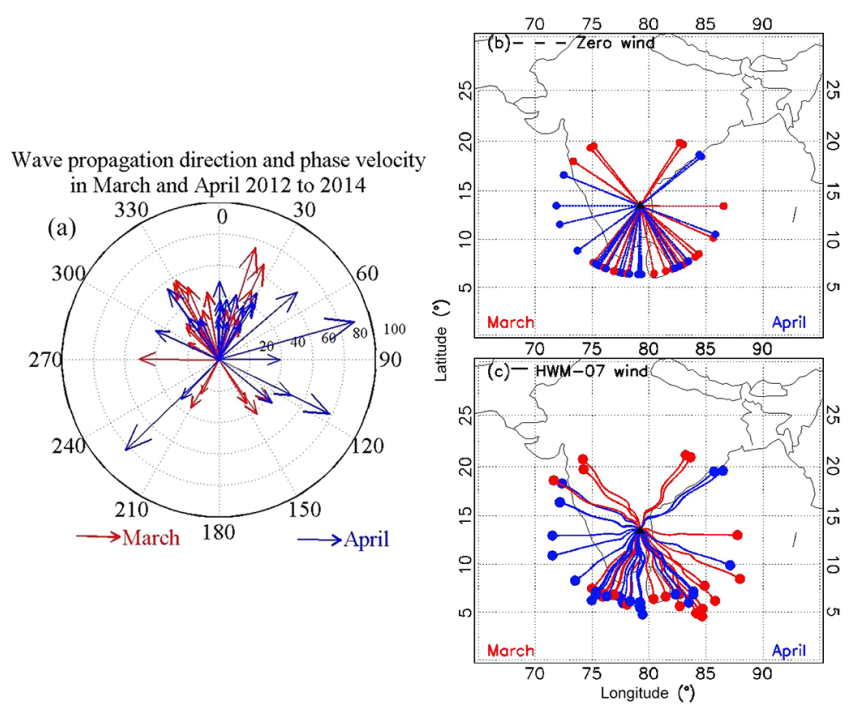

Figure 5. (a) shows the observed phase speed and direction of horizontal propagation of gravity waves, and Fig. $5 \mathrm{~b}$ and $\mathrm{c}$ denote the reverse-ray-tracing results in (b) zero wind as well as in (c) HWM07 model wind condition in March-April 2012 and 2014 and April 2013. The red-colored arrows (lines) indicate March events, while blue arrows (lines) show the events noted in April. In the polar plot the inner dotted circles indicate the horizontal phase speed of the observed wave at an interval of $20 \mathrm{~m} \mathrm{~s}^{-1}$. In right-side plots red (blue) dots indicate the source origin in March (April).

about $90 \%$ of waves have their periods in the $615 \mathrm{~min}$ range, with only $2 \%$ of waves having periods of more than $15 \mathrm{~min}$.

\subsection{Wave propagation and sources of the wave}

Figure 5a shows the horizontal propagation direction of the small-scale gravity waves, and Figs. $5 \mathrm{~b}$ and $\mathrm{c}$ show the reverse ray paths (with zero wind condition (Fig. 5b) and with estimated HWM winds (Fig. 5c)) and their source areas., Red symbols correspond to March, and blue ones to April. In Fig. $5 b$ and c, the red line (dot) indicates ray path (source areas) in March, and the blue line (dot) indicates ray path (source areas) in April. Most of the times, waves propagate 
Table 1. Predominant wave propagation directions during different months.

\begin{tabular}{lrrrrr}
\hline Month and year & \multicolumn{2}{c}{ Wave propagations in different direction (degree) } & \multirow{2}{*}{ Total } \\
\cline { 2 - 5 } & $\begin{array}{r}\text { East } \\
(46-135)\end{array}$ & $\begin{array}{r}\text { South } \\
(136-225)\end{array}$ & $\begin{array}{r}\text { West } \\
(226-315)\end{array}$ & $\begin{array}{r}\text { North } \\
(316-45)\end{array}$ & \\
\hline Mar 2012 & Nil & 2 & 2 & 10 & 14 \\
Apr 2012 & 2 & Nil & 1 & 4 & 7 \\
Apr 2013 & 1 & Nil & Nil & 4 & 5 \\
Mar 2014 & 1 & 2 & 1 & 5 & 9 \\
Apr 2014 & 3 & 2 & Nil & 10 & 15 \\
\hline Total & 7 & 6 & 4 & 33 & 50 \\
\hline
\end{tabular}

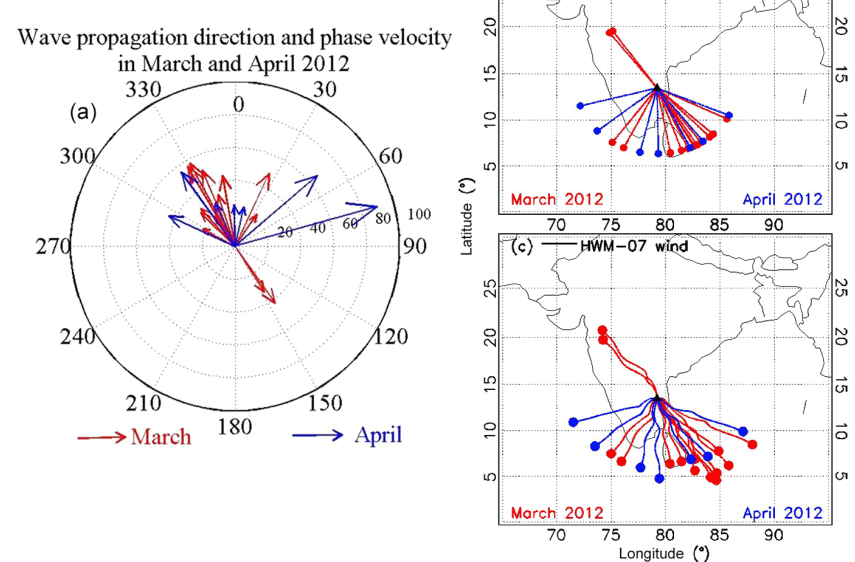

Figure 6. As in Fig. 5 but for the year 2012.

northward, with only a few events showing southward propagation (as seen most clearly in Table 1). An earlier report from the Indian subcontinent by Lakshmi Narayanan and Gurubaran (2013) from Tirunelveli $\left(8.7^{\circ} \mathrm{N}\right)$, based on data corresponding to the year 2007 suggested that during equinox season waves mainly propagate towards the north, which is similar to the present results. It is reasonable to assume, as the waves propagate away from their source regions (e.g., Pautet et al., 2005), that the wave generation must be located somewhere in the south of the measurement location.

A comparison between our results and some of the earlier small-scale wave measurements is made in Table 2 (please note that the list is not exhaustive). It has to be noticed that wavelengths phase velocity and observed wave periods are within the range reported by the earlier investigations. Furthermore, most small-scale waves observed in the mesosphere have their origin in lower-atmospheric processes such as tropospheric convection, wind shear, wave-wave interaction or secondary wave generation (e.g., Alexander, 1996; Holton and Alexander, 1999; Pandya and Alexander, 1999; Piani et al., 2000; Fritts and Alexander, 2003; Taori et al.,

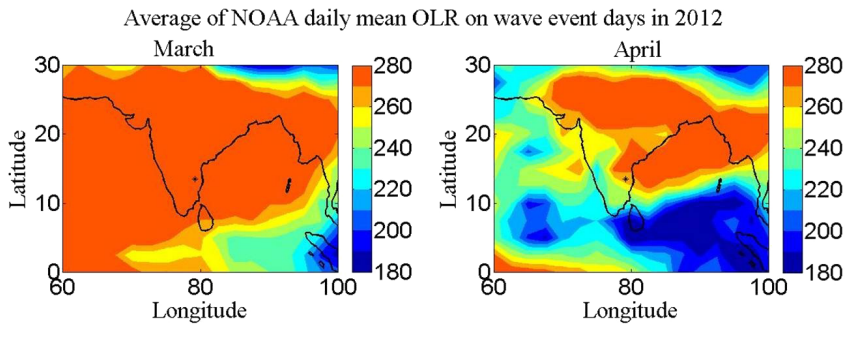

Figure 7. The average of daily mean OLR for the days when waves were observed in airglow image data in March and April 2012. The location of measurements is shown as an asterisk.

2012; Pramitha et al., 2015, Horinouchi et al., 2003; Nakamura et al., 2003; Pautet et al., 2005). Of particular relevance to our observations is the report by Pautet et al. (2005), in which based on 19 wave events it was clearly shown that waves were generated by the convection and propagated away from their sources (convective clouds). The present investigation shows that for $\sim 66 \%$ wave events the sources were located within the convective clouds and that, for another $\sim 14 \%$ of wave events, sources were located near the convective region. The remaining $20 \%$ of wave events were probably generated by non-convective sources. Furthermore, to understand the monthly and yearly variation of the source region, we look into the average of the daily mean NOAAOLR for the days when airglow observations were made.

Figure 6a shows the propagation direction and phase velocity of the wave events noted in March-April 2012, and Fig. $6 \mathrm{~b}$ and $\mathrm{c}$ shows the reverse-ray-tracing paths with their source areas (Fig. $6 \mathrm{~b}$ for zero wind condition, while Fig. $6 \mathrm{c}$ show ray paths using HWM wind). Red arrows indicate the wave propagation angle in March, and the blue arrows indicate the wave propagation angle in April. Likewise, in rightside plots the red line (dot) indicates ray path (source areas) in March, and the blue line (dot) indicates ray path (source areas) in April. Out of 21 wave events, 14 are propagating towards the northwest. Few waves were traveling towards the northeast, while only two wave events had their propagation towards the south. The average of daily mean OLR data dur- 
Table 2. Comparison of the present results with earlier small-scale wave measurements.

\begin{tabular}{|c|c|c|c|c|c|}
\hline Station & Latitude, longitude & $\begin{array}{l}\text { Horizontal } \\
\text { wavelength }(\mathrm{km})\end{array}$ & $\begin{array}{l}\text { Phase } \\
\text { speed } \\
\left(\mathrm{m} \mathrm{s}^{-1}\right)\end{array}$ & $\begin{array}{l}\text { Observed } \\
\text { period } \\
(\min )\end{array}$ & References \\
\hline Shigaraki & $35^{\circ} \mathrm{N}, 136^{\circ} \mathrm{E}$ & $5-60$ & $0-100$ & $0-30$ & Nakamura et al. (1999) \\
\hline Rikubetsu & $43.5^{\circ} \mathrm{N}, 143.8^{\circ} \mathrm{E}$ & $\begin{array}{l}10-42(\mathrm{OH}) \\
10-58\left(\mathrm{O}^{1} \mathrm{~S}\right)\end{array}$ & $\begin{array}{l}\sim 0-100 \\
\sim 10-110\end{array}$ & & Ejiri et al. (2003) \\
\hline Cachoeira Paulista & $23^{\circ} \mathrm{S}, 45^{\circ} \mathrm{W}$ & $5-60$ & $10-80$ & $6-34$ & Medeiros et al. (2003) \\
\hline Tanjungsari & $6.9^{\circ} \mathrm{S}, 107.9^{\circ} \mathrm{E}$ & $3-80$ & $10-95$ & $5-13$ & Nakamura et al. (2003) \\
\hline Darwin & $12.4^{\circ} \mathrm{S}, 131^{\circ} \mathrm{E}$ & $20-90$ & $0-90$ & & Suzuki et al. (2004) \\
\hline Buckland Park & $34.5^{\circ} \mathrm{S}, 138.5^{\circ} \mathrm{E}$ & $20-200$ & $20-250$ & $40-240$ & Ding et al. (2004) \\
\hline Cariri & $7.4^{\circ} \mathrm{S}, 36.5^{\circ} \mathrm{W}$ & $\sim 5-40$ & $1-90$ & $\sim 5-30$ & Medeiros et al. (2007); Wrasse et al. (2006) \\
\hline Resolute Bay & $74.7^{\circ} \mathrm{N}, 265.1^{\circ} \mathrm{E}$ & $\sim 10-70$ & $10-110$ & & Suzuki et al. (2009a) \\
\hline Kototabang & $0.2^{\circ} \mathrm{S}, 100.3^{\circ} \mathrm{E}$ & $25-95$ & $5-125$ & & Suzuki et al. (2009b) \\
\hline Mt. Bohyun & $36.2^{\circ} \mathrm{N}, 128.9^{\circ} \mathrm{E}$ & $10-45$ & $0-80$ & $5-45$ & Kim et al. (2010) \\
\hline Xinglong & $40.2^{\circ} \mathrm{N}, 117.4^{\circ} \mathrm{E}$ & $\sim 10-55$ & $10-100$ & $2-20$ & Q. Li et al. (2011) \\
\hline Maui & $20.7^{\circ} \mathrm{N}, 156.3^{\circ} \mathrm{W}$ & $\sim 10-120$ & $\sim 0-150$ & $\sim 5-30$ & Z. Li et al. (2011) \\
\hline Syowa Station & $69^{\circ} \mathrm{S}, 0-40^{\circ} \mathrm{E}$ & $10-60$ & $0-150$ & $3-65$ & Matsuda et al. (2014) \\
\hline Tirunelveli & $8.7^{\circ} \mathrm{N}, 77.8^{\circ} \mathrm{E}$ & $5-45$ & $10-140$ & $3-20$ & Lakshmi Narayanan and Gurubaran (2013) \\
\hline Gadanki & $13.5^{\circ} \mathrm{N}, 79.2^{\circ} \mathrm{E}$ & $12-42$ & $20-90$ & $4-20$ & Present study \\
\hline
\end{tabular}
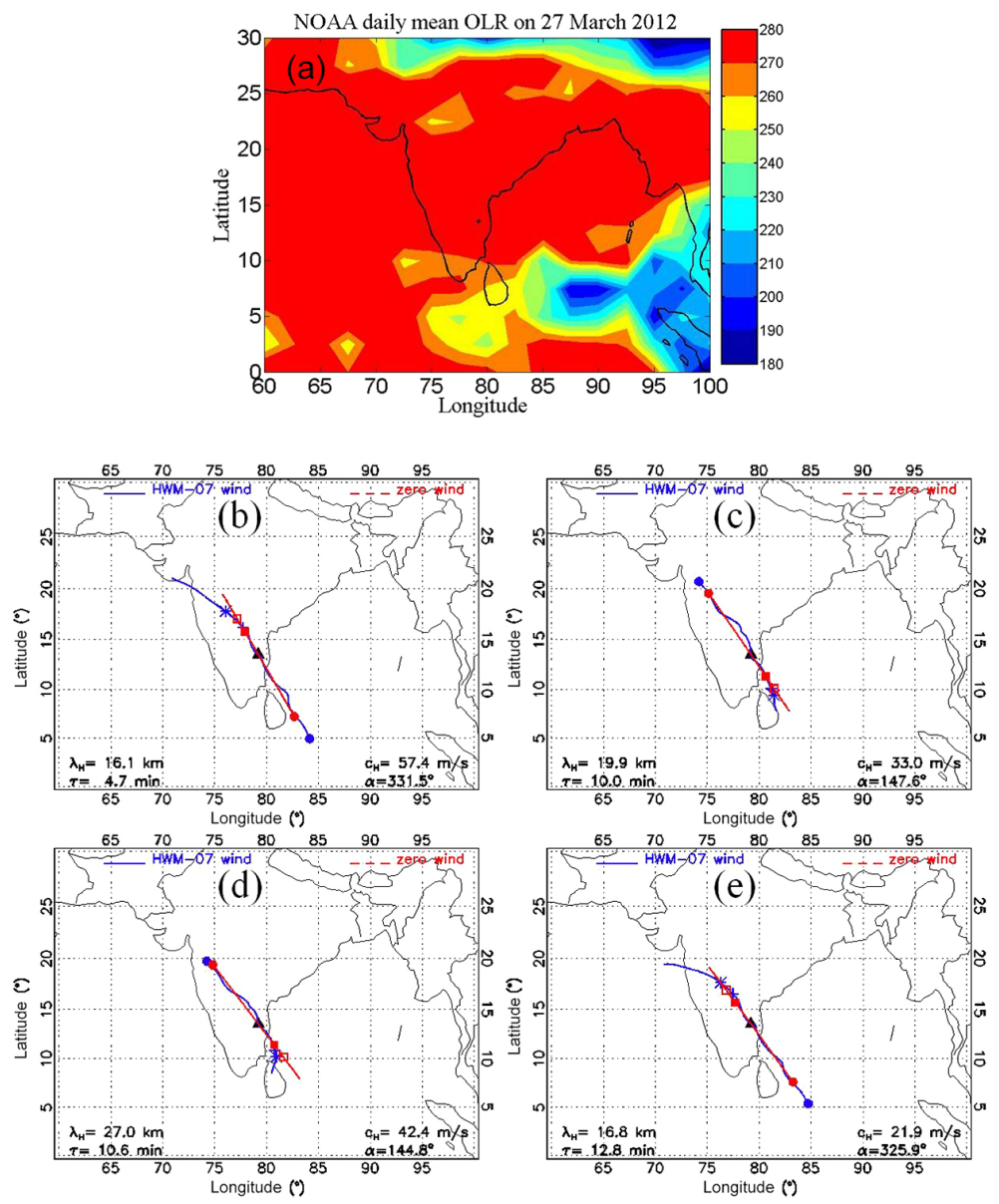

Figure 8. Daily mean OLR data (a) and ray paths for the different wave events of 27 March 2012 (b-e). Blue (red) lines are for model winds (zero winds). Gadanki location is black triangle in (b-e). Plus and filled square symbols indicate where the gravity waves have the maximum amplitude into the thermophere. Star and open square show where/when the gravity waves have less than $1 \%$ of their initial amplitude. 


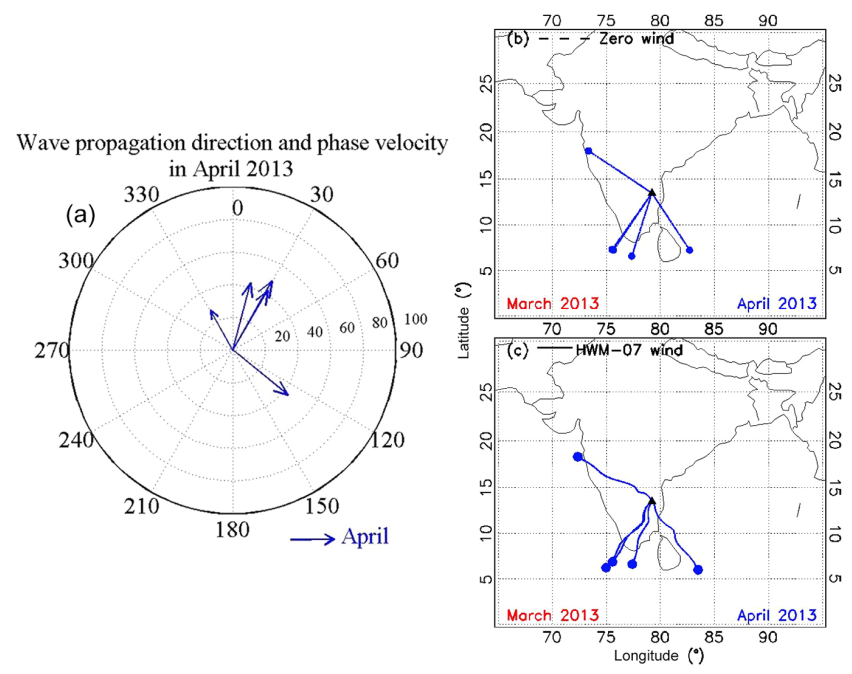

Figure 9. As in Fig. 5 but for the year 2013.

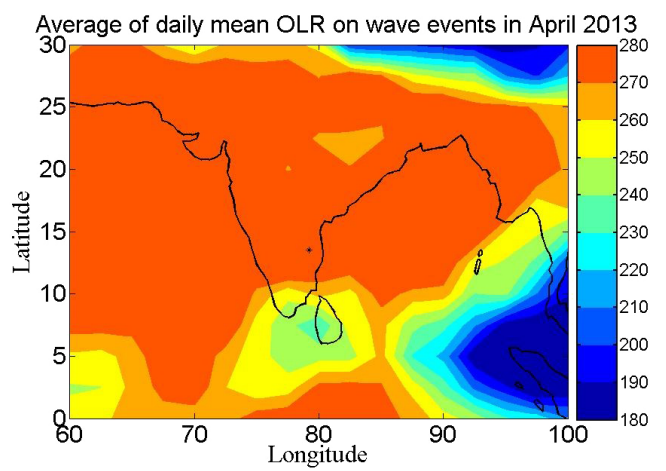

Figure 10. As in Fig. 7 but for the year 2013.

ing the observations is plotted in Fig. 7. In the OLR low intensity $(<200)$ corresponds to the deep convection. The left map shows the averaged OLR values for March 2012, while the right map is for April 2012. The location of measurement is shown as an asterisk. It is clear that during the March there is a deep convection occurring at the southeast part of the map; hence the waves propagating away from these sources shall have the propagation in the northwest direction, which is consistent with the observations. During April apart from the deep convection at the southeast location, there is a convective patch on the southwest side of the map. In this regard, observations suggesting that in the April months waves propagated in the northeast and northwest directions (in Fig. 6a) are likely due to the fact that their sources were associated with the convective plumes noted in the OLR data. There are two wave events which show southward propagation (on 27 March 2012) which we showcase as a special case in the following.

On 27 March 2012, we noted four wave events, two of them propagating towards the northwest and another two waves progressing to the southeast (as mentioned earlier). On

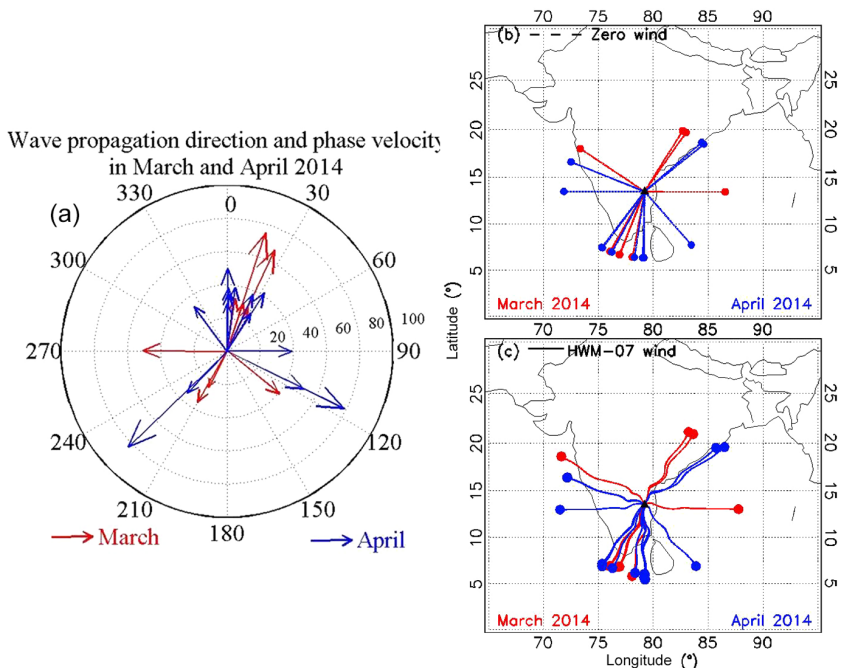

Figure 11. As in Fig. 5 but for the year 2014.

this night, the daily mean OLR data and reverse ray paths are plotted in Fig. 8. There were some isolated convective activities occurring in the northwest locations as well as a strong convection in the southeast locations. Together with the OLR patches, the ray path also terminates near the convective locations. There were some isolated convective processes at $20^{\circ} \mathrm{N}, 76^{\circ} \mathrm{E}$ (source, http://www.mosdac.gov.in), which may have triggered these waves. Please note that only those events which could overcome the wind filtering mechanisms could be observed. Typical zonal and meridional winds during March-April months over Tirunelveli $\left(8.7^{\circ} \mathrm{N}, 77.8^{\circ} \mathrm{E}\right)$ are reported to be $\sim 15$ and $18 \mathrm{~m} \mathrm{~s}^{-1}$ (Sivakandan et al., 2015) in the $85-100 \mathrm{~km}$ altitude range, and HWM-07 wind estimates also suggest the maximum winds to be less than $20 \mathrm{~m} \mathrm{~s}^{-1}$ at these altitudes. Thus, waves having a phase velocity of more than $20 \mathrm{~m} \mathrm{~s}^{-1}$ will not be blocked by the horizontal winds and may propagate to their preferred directions governed by the source properties. We believe that this is why the waves have phase velocities greater than $20 \mathrm{~m} \mathrm{~s}^{-1}$. Therefore, we believe that this event of abnormal wave propagation has been well captured by the reverse-ray-tracing analysis.

The propagation and phase velocity of the wave events noted in April 2013 as well as their reverse-ray-path results were plotted in Fig. 9. Out of five wave events, three waves were propagated in northeasterly directions, one wave northward, and one to the southeast. Furthermore, an important point is that all the waves had their phase velocity higher than $20 \mathrm{~m} \mathrm{~s}^{-1}$. The OLR data corresponding to April 2013 events are plotted in Fig. 10, where it is clear that there were convective regions in the southern side of the measuring site which most likely triggered the waves which were propagating to the northeast and northwest. Together with one of the events propagating southeast, on this day daily mean OLR shows a convective region at around $20^{\circ} \mathrm{N}, 70^{\circ} \mathrm{E}$ (figure not shown here). Furthermore, as in earlier cases, for all these 

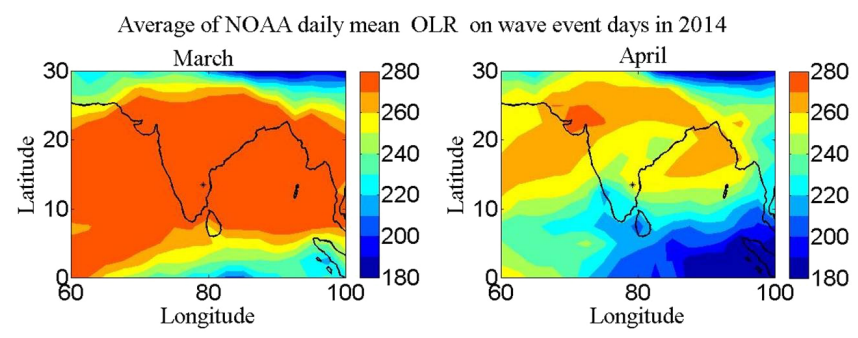

Figure 12. As in Fig. 7 but for the year 2014.

wave events the reverse ray paths also terminate in the convective region.

Figure 11a depicts the gravity wave propagation direction and phase velocity, and Fig. $11 \mathrm{~b}$ and c depict the reverseray-tracing results corresponding to March-April 2014. This year's wave directions show deviations compared to the year 2012. In the year 2012 waves propagated dominantly to the northwest, while in 2014 waves were moving to the northeast, with a substantial number of waves in southward directions. The OLR corresponding to March and April 2014 is shown in Fig. 12. It has to be noted that there are convective processes occurring in southward as well as northward directions, and thus the waves triggered by these sources are reflected in our measurements. This is consistent with our ray-tracing results. However, from the ray-tracing source area it is clear that the waves propagating almost in zonal directions are not generated by a convective source. Of these, one of the events (17 March 2012) was discussed earlier to be caused by the wind shears (Pramitha et al., 2015). Other sources may be mesospheric-thermospheric body forcing or secondary waves (e.g., Fritts and Alexander, 2003; Vadas and Fritts, 2009; Vadas and Liu, 2011), where convection may remain as the prime source $(\sim 66 \%)$ of gravity waves.

\section{Summary}

The image measurements of OI557.7 nm nightglow during the spring season over Indian low latitudes show conspicuous signatures of upper-mesospheric waves. The horizontal wavelengths ranged from 10 to $42 \mathrm{~km}$ and were mostly found to propagate towards the north side of the location of the measurements. Over the Indian subcontinent, often the lower-atmospheric convection activities occur south of Gadanki, which we have also noted in the OLR data. The directions of wave propagation and reverse-ray-tracing results were found to be consistent with the source being in the south, which suggest that $\sim 66 \%$ of observed wave events may have been generated by tropospheric convection and another $14 \%$ of waves were coming from near the convective region. And the remaining $20 \%$ of waves were generated by purely non-convective source mechanisms. Present investigation prominently shows that convection and its associated processes are the main source for the generation of smallscale gravity waves over the low-latitude Indian sector.

Acknowledgements. The present work is supported by the Department of Space, Government of India. We acknowledge Liyakat Basha, V. Kamalakar, and R. Goenka for their help in carrying out night airglow measurements. We give thanks to C. A. Smith of NOAA Earth System Research Laboratory for providing the interpolated OLR data (source: www.esrl.noaa.gov/psd/data/gridded/data.interp_OLR.html).

I. Paulino thanks the $\mathrm{CNPq}$ for the financial support (grant no. 478117/2013-2).

Edited by: M. Rapp

\section{References}

Alexander, M. J.: A simulated spectrum of convectively generated gravity waves: Propagation from the tropopause to the mesopause and effects on the middle atmosphere, J. Geophys. Res., 101, 1571-1588, doi:10.1029/95JD02046, 1996.

Ding, F., Yuan, H., Wan, W., Reid, I. M., and Woithe, J. M.: Occurrence characteristics of medium-scale gravity waves observed in $\mathrm{OH}$ and $\mathrm{OI}$ nightglow over Adelaide $\left(34.5^{\circ} \mathrm{S}, 138.5^{\circ} \mathrm{E}\right)$, J. Geophys. Res. D Atmos., 109, 1-10, doi:10.1029/2003JD004096, 2004.

Drob, D. P., Emmert, J. T., Crowley, G., Picone, J. M., Shepherd, G. G., Skinner, W., Hays, P., Niciejewski, R. J., Larsen, M., She, C.Y., Meriwether, J. W., Hernandez, G., Jarvis, M. J., Sipler, D. P., Tepley, C. A., O’Brien, M. S., Bowman, J. R., Wu, Q., Murayama, Y., Kawamura, S., Reid, I. M., and Vincent, R. A.: An empirical model of the Earth's horizontal wind fields: HWM07. J. Geophys. Res., 113, 12304, doi:10.1029/2008JA013668, 2008.

Ejiri, M. K., Shiokawa, K., Ogawa, T., Igarashi, K., Nakamura, T., and Tsuda, T.: Statistical study of short-period gravity waves in $\mathrm{OH}$ and $\mathrm{OI}$ nightglow images at two separated sites, J. Geophys. Res., 108, 4679, doi:10.1029/2002JD002795, 2003.

Fritts, D. C. and Alexander, M. J.: Gravity wave dynamics and effects in the middle atmosphere, Rev. Geophys., 41, 1003, doi:10.1029/2001RG000106, 2003.

Holton, J. R. and Alexander, M. J.: Gravity waves in the mesosphere generated by tropospheric convection, Tellus, Ser. B Chem. Phys. Meteorol., 51, 45-58, doi:10.3402/tellusa.v51i1.12305, 1999.

Horinouchi, T., Pawson, S., Shibata, K., Langematz, U., Manzini, E., Giorgetta, M. A., Sassi, F., Wilson, R. J., Hamilton, K., de Grandpré, J., and Scaife, A. A.: Tropical cumulus convection and upward-propagating waves in middle-atmospheric GCMs, J. Atmos. Sci., 60, 2765-2782, doi:10.1175/15200469(2003)060<2765:TCCAUW>2.0.CO;2, 2003.

Kim, Y. H., Lee, C., Chung, J.-K., Kim, J.-H., and Chun, H.-Y.: Seasonal variations of mesospheric gravity waves observed with an airglow all-sky camera at Mt. Bohyun, Korea $\left(36^{\circ} \mathrm{N}\right)$, J. Astron. Sp. Sci., 27, 181-188, doi:10.5140/JASS.2010.27.3.181, 2010.

Lakshmi Narayanan, V. and Gurubaran, S.: Statistical characteristics of high frequency gravity waves observed by $\mathrm{OH}$ airglow imaging from Tirunelveli $\left(8.7^{\circ} \mathrm{N}\right)$, J. Atmos. Solar-Terrestrial Phys., 92, 43-50, doi:10.1016/j.jastp.2012.09.002, 2013. 
Li, Q., Xu, J., Yue, J., Yuan, W., and Liu, X.: Statistical characteristics of gravity wave activities observed by an $\mathrm{OH}$ airglow imager at Xinglong, in northern China, Ann. Geophys., 29, 1401-1410, doi:10.5194/angeo-29-1401-2011, 2011.

Li, Z., Liu, A. Z., Lu, X., Swenson, G. R. and Franke, S. J.: Gravity wave characteristics from $\mathrm{OH}$ airglow imager over Maui, J. Geophys. Res. Atmos., 116, D22115, doi:10.1029/2011JD015870, 2011.

Lighthill, J.: Waves in Fluids, Cambridge University Press, New York, 504 pp., 1978.

Liu, A. Z. and Swenson, G. R.: A modeling study of $\mathrm{O}_{2}$ and $\mathrm{OH}$ airglow perturbations induced by atmospheric gravity waves, J. Geophys. Res., 108, 4151, doi:10.1029/2002JD002474, 2003.

Marks, C. J. and Eckermann, S. D.: A three-dimensional nonhydrostatic ray-tracing model for gravity waves: formulation and preliminary results for the middle atmosphere, J. Atmos. Sci., 52, 1959-1984, 1995.

Matsuda, T. S., Nakamura, T., Ejiri, M. K., Tsutsumi, M., and Shiokawa, K.: New statistical analysis of the horizontal phase velocity distribution of gravity waves observed by airglow imaging, J. Geophys. Res. Atmos., 119, 9707-9718, doi:10.1002/2014JD021543, 2014.

Medeiros, A. F., Taylor, M. J., Takahashi, H., Batista, P. P., and Gobbi, D.: An investigation of gravity wave activity in the lowlatitude upper mesosphere: Propagation direction and wind filtering, J. Geophys. Res., 108, 4411, doi:10.1029/2002JD002593, 2003.

Medeiros, A. F., Takahashi, H., Buriti, R. A., Fechine, J., Wrasse, C. M., and Gobbi, D.: MLT gravity wave climatology in the South America equatorial region observed by airglow imager, Ann. Geophys., 25, 399-406, doi:10.5194/angeo-25-399-2007, 2007.

Mukherjee, G. K.: The signature of short-period gravity waves imaged in the OI $557.7 \mathrm{~nm}$ and near infrared $\mathrm{OH}$ nightglow emissions over Panhala, J. Atmos. Solar-Terr. Phys., 65, 1329-1335, 2003

Mukherjee, G. K., Pragati Sikha, R., Parihar, N., Ghodpage, R., and Patil, P. T.: Studies of the wind filtering effect of gravity waves observed at Allahabad $\left(25.45^{\circ} \mathrm{N}, 81.85^{\circ} \mathrm{E}\right)$ in India, Earth Planets Space, 62, 309-318, 2010.

Nakamura, T., Higashikawa, A., and Tsuda, T.: Seasonal variation of gravity waves observed with an $\mathrm{OH}$ CCD imager at Shigaraki $\left(35^{\circ} \mathrm{N}, 136^{\circ} \mathrm{E}\right)$, Japan, Adv. Sp. Res., 24, 561-564, doi:10.1016/S0273-1177(99)00201-X, 1999.

Nakamura, T., Aono, T., Tsuda, T., Admiranto, A. G., Achmad, E., and Suranto, E.: Mesospheric gravity waves over a tropical convective region observed by $\mathrm{OH}$ airglow imaging in Indonesia, Geophys. Res. Lett., 30, 1882, doi:10.1029/2003GL017619, 2003

Pandya, R. E. and Alexander, M. J.: Linear stratospheric gravity waves above convective thermal forcing, J. Atmos. Sci., 56, 2434-2446, doi:10.1175/15200469(1999)056<2434:LSGWAC>2.0.CO;2, 1999.

Parihar, N. and Taori, A.: An investigation of long-distance propagation of gravity waves under CAWSES India Phase II Programme, Ann. Geophys., 33, 547-560, doi:10.5194/angeo-33547-2015, 2015.

Paulino, I., Takahashi, H., Vadas, S. L., Wrasse, C. M., Sobral, J. H. A., Medeiros, A. F., Buriti, R. A., and Gobbi, D.: Forward ray-tracing for medium-scale gravity waves observed during the COPEX campaign, J. Atmos. Solar-Terr. Phys., 90-91, 117-123, doi:10.1016/j.jastp.2012.08.006, 2012.

Pautet, P. D., Taylor, M. J., Liu, A. Z., and Swenson, G. R.: Climatology of short-period gravity waves observed over northern Australia during the Darwin Area Wave Experiment (DAWEX) and their dominant source regions, J. Geophys. Res.-Atmos., 110, 113, doi:10.1029/2004JD004954, 2005.

Piani, C., Durran, D., Alexander, M. J., and Holton, J. R.: A numerical study of three-dimensional gravity waves triggered by deep tropical convection and their role in the dynamics of the QBO, J. Atmos. Sci., 57, 3689-3702, doi:10.1175/15200469(2000)057<3689:ANSOTD>2.0.CO;2, 2000.

Picone, J. M., Hedin, A. E., Drob, D. P., and Aikin, A. C.: NRLMSISE-00 empirical model of the atmosphere: statistical comparisons and scientific issues, J. Geophys. Res., 107, 1468, doi:10.1029/2002JA009430, 2002.

Pragati, R. S., Parihar, N., Ghodpage, R., and Mukherjee, G. K.: Characteristics of gravity waves in the upper mesospheric region observed by OH airglow, Current Science 98, 392-397, 2010.

Pramitha, M., Venkat Ratnam, M., Taori, A., Krishna Murthy, B. V., Pallamraju, D., and Vijaya Bhaskar Rao, S.: Evidence for tropospheric wind shear excitation of high-phase-speed gravity waves reaching the mesosphere using the ray-tracing technique, Atmos. Chem. Phys., 15, 2709-2721, doi:10.5194/acp-15-27092015, 2015.

Sivakandan, M., Taori, A., Sathishkumar, S., and Jayaraman, A.: Multi-instrument investigation of a mesospheric gravity wave event absorbed into background, J. Geophys. Res., 120, 31503159,, doi:10.1002/2014JA020896, 2015.

Smith, A. K.: Global Dynamics of the MLT, Surv. Geophys, 33, 1177-1230, doi:10.1007/s10712-012-9196-9, 2012.

Suzuki, S., K. Shiokawa, Y. Otsuka, T. Ogawa, and P. Wilkinson, Statistical characteristics of gravity waves observed by an allsky imager at Darwin, Australia, J. Geophys. Res., 109, D20S07, doi:10.1029/2003JD004336, 2004.

Suzuki, S., Shiokawa, K., Hosokawa, K., Nakamura, K., and Hocking, W. K.: Statistical characteristics of polar cap mesospheric gravity waves observed by an all-sky airglow imager at Resolute Bay, Canada, J. Geophys. Res. Sp. Phys., 114, 1-8, doi:10.1029/2008JA013652, 2009a.

Suzuki, S., Shiokawa, K., Liu, A. Z., Otsuka, Y., Ogawa, T., and Nakamura, T.: Characteristics of equatorial gravity waves derived from mesospheric airglow imaging observations, Ann. Geophys., 27, 1625-1629, doi:10.5194/angeo-27-1625-2009, 2009 b.

Taori, A., Raizada, S., Ratnam, M. V., Tepley, C. A., Nath, D., and Jayaraman, A.: Role of Tropical Convective Cells in the Observed Middle Atmospheric Gravity Wave Properties from Two Distant Low Latitude Stations, Earth Sci. Res., 1, 87-97, doi:10.5539/esr.v1n1p87, 2012.

Taori, A., Jayaraman, A., and Kamalakar, V.: Imaging of mesosphere-thermosphere airglow emissions over Gadanki $\left(13.5^{\circ} \mathrm{N}, 79.2^{\circ} \mathrm{E}\right)$ - first results, J. Atmos. Solar-Terrestrial Phys., 93, 21-28, doi:10.1016/j.jastp.2012.11.007, 2013.

Taylor, M. J. and Hapgood, M. A.: Identification of a thunderstorm as a source of short period gravity waves in the upper atmospheric nightglow emissions, Planet. Space Sci., 36, 975-985, doi:10.1016/0032-0633(88)90035-9, 1988. 
Vadas, S. L. and Fritts, D. C.: Thermospheric responses to gravity waves: influences of increasing viscosity and thermal diffusivity, J. Geophys. Res., 110, 15103, doi:10.1029/2004JD005574, 2005.

Vadas, S. L. and Fritts, D. C.: Reconstruction of the gravity wave field from convective plumes via ray tracing, Ann. Geophys., 27, 147-177, doi:10.5194/angeo-27-147-2009, 2009.

Vadas, S. L. and Liu, H.-L.: Generation of large-scale gravity waves and neutral winds in the thermosphere from the dissipation of convectively generated gravity waves, J. Geophys. Res., 114, A10310, doi:10.1029/2009JA014108, 2009.

Walterscheid, R. L., Hecht, J. H., Vincent, R. A., Reid, I. M., Woithe, J., and Hickey, M. P.: Analysis and interpretation of airglow and radar observations of quasi-monochromatic gravity waves in the upper mesosphere and lower thermosphere over Adelaide, Australia $\left(35^{\circ} \mathrm{S}, 138^{\circ} \mathrm{E}\right)$, J. Atmos. Solar-Terrestrial Phys., 61, 461-478, doi:10.1016/S13646826(99)00002-4, 1999.
Wrasse, C. M., Nakamura, T., Takahashi, H., Medeiros, A. F., Taylor, M. J., Gobbi, D., Denardini, C. M., Fechine, J., Buriti, R. A., Salatun, A., Suratno, Achmad, E., and Admiranto, A. G.: Mesospheric gravity waves observed near equatorial and low-middle latitude stations: wave characteristics and reverse ray tracing results, Ann. Geophys., 24, 3229-3240, doi:10.5194/angeo-243229-2006, 2006. 